\title{
EXPERIMENTAL STUDIES ON PROPERTIES OF SULFUR MODIFIED BINDER WITH AGING
}

\author{
Kumkum Priyadarsini \\ M.Tech Student (2017-2019) of VSSUT, Burla, Odisha, India \\ Jhunarani Ojha \\ Assistant Professor, VSSUT, Burla, Odisha, India
}

\begin{abstract}
The bituminous pavement failure occurs due to excessive traffic loads and different climatic conditions. To protect the pavement failure one of the measure is to enhance the properties of bitumen and its quality and it may achieved by modification of the bitumen. In this research work, sulfur is used as modifier due to it's readily availability in local market with less cost. The huge production of sulfur from petro chemical as well as gas, oil refining industries in our country with less utilization should be the main encouraging source for using it as modifier. The addition of sulfur with bitumen can improve the characteristics as well as physical properties of bitumen. Inside the research, sulfur is being mixed with virgin bitumen (1 to 9\% with increasing $1 \%$ by total weight of binder) at a specified mixing time and temperature. The aging effect of virgin and SMB is also discussed through carrying out Rolling thin-film oven (RTFO) and Pressure aging vessel (PAV) tests. The outcome of the present investigations represents that the bitumen binder becomes harder after modification with sulfur producing appropriate results as per provision of code but the aging of modified binder not becoming much harder as compared with virgin bitumen and it also satisfying the guidelines.
\end{abstract}

Keywords: Pavement; Modified Binder; Sulfur; Short Term Aging; Long Term Aging; Physical property.

Cite this Article: Kumkum Priyadarsini and Jhunarani Ojha, Experimental Studies on Properties of Sulfur Modified Binder with Aging. International Journal of Civil Engineering and Technology, 11(2), 2020, 140-155.

https://iaeme.com/Home/issue/IJCIET?Volume $=11 \&$ Issue $=2$

\section{INTRODUCTION}

The excessive growth of vehicular weights with contact pressure of tire in different seasonal circumstances is the main cause of bitumen pavement life cycle issue which increase the demand on the flexible bituminous pavement. For reduction of distress like rutting, cracking effect of pavement, the property enhancement of bitumen is required. The better performances of a bituminous pavement depend upon the composition and properties of bitumen as a result 
of which modified bitumen has been introduced. There are several modifiers used in bitumen binders such as physical, chemical and other types of modifier. The physical modifiers are categorized in to three groups such as Thermoplastic elastomers, Thermoplastic polymer and thermosetting polymer. The chemical modifiers are Lignin and Sulfur and fiber, adhesion improvers, Anti-oxidants, natural bitumen, fillers and extenders are goes under other types of modifiers. Here sulfur from chemical groups of modifiers has been used for binder modification. The main aim of introducing modifiers in bitumen binder is to increase the properties like stripping potential, increase stability, and reduce flow, stiffness modulus, rutting resistance of the pavement and it also strengthen the properties with reduction of cracking effect with growing the life span of flexible pavement [1].

The large quantity of Sulphur is produces as a by-product of petro-chemical as well as oil and gas refining industries but its small utilization in the country has been a challenging problem. About 70 million tons of sulfur is produced worldwide and its consumption is too less. To overcome such issue, here we utilized sulfur as a modifier in the bituminous binder to improve the properties and also recycle the waste like sulfur. From the technical point of view, sulfur addition with bituminous binder partially replaces bitumen as well as decrease the amount of asphalt, acts as a mineral filler, improves the stiffness of pavement and this has no disadvantageous effect on low-temperature properties.

The change in physical properties of the bituminous binder by cause of change in its chemical composition is called bitumen aging. It makes the bituminous binder stiffer and more brittle which rises liability of pavement failure. Loss of oily components of the bituminous binder by volatility, the reaction between oxygen and bitumen molecules changing the chemical composition of bitumen and molecular structuring (steric hardening or physical hardening), exudative hardening are the main factors that affect the ageing [2].The aging affects the pavement by formation of cracking and Ravelling. The pavement surface cracking may grows up binders aging property because of raised vulnerability surface to climatic oxygen. Bitumen aging develops by 2 categories i.e. Short Term Aging at high temperatures which is greater than $130^{\circ} \mathrm{c}$ with higher oxidation rate at time of mixing, laying, transporting at construction site and long term aging is a slow oxidative process generally it appears on the top surface course of pavement at ambient temperature through life span. The aging performs a major act on durability of road surface. The pavement has used with cracking due to more stiffness and brittle quality. So the aging of binder should be determined for unmodified and modified binder for checking their quality for a good quality pavement.

In this research work, Sulfur is used as a modified binder and its properties has been checked as well as the aging effect (Short Term Aging) also determined. Sulfur has modifying with varying percentages (1\% to $9 \%$ ), and the modified binder's property(physical) will checked through performing tests like "Penetration, Softening point, Ductility, Elastic recovery, Viscosity, Rolling Thin Film Oven (RTFO) and Pressure Aging Vessel (PAV) Tests". By conducting various tests on binders according to the availability of our laboratory, it has been observed that the modified binders can change the physical properties of virgin bitumen. The exception of this work from previous research work is that the Sulfur Modified Binder properties checked by PAV test and then the properties of natural bitumen and Sulfur Modified Bitumen is compared, and observation of variations have been investigated. This work also represents all the results as per standard specifications and represented by tables and graphs and even variations of results in percentages and values given.

The other part of paper is catalogued in to following. Section II describes previously related work, with particular focus on the studies of Sulfur modified bitumen and its properties. Experimental investigation about the properties of bitumen and reference codes for various features are described in section III. In section IV, the overall set up of experiment, 
the method to handle the laboratory tests are given. The outcomes of the various experiments and the data obtained from the experimental results are analyzed and discussed inside part V. Lastly about conclusive opinion have been epitomized summarized inside VI zone. based on the experiments and their outcomes obtained from the experiments conducted for Sulfur modified bitumen with ageing.

\section{RELATED WORK}

This section of the paper represents the explanation and literature survey about the research work. It expresses the current state of knowledge about various types of modifiers, their importance in bituminous binder, Tests and research works conducted previously on different modifiers and especially about the Sulfur Modified Binder with its properties on various research work over the topic.

Sabina, Tabrez A. Khan et. al. (2009) states the performance of critical analysis of waste plastic. This research work comprises the comparisons between the Performances of properties of waste plastic/polymer modified bituminous concrete mixtures with conventional bituminous mixtures. They found that the aggregate coating with waste PP , should improve the AIV, LAAV and water absorption capacity .More increment in such parameters like Marshall stability, rutting, ITS obtained by modified waste plastic/pp. and modified bituminous mixtures. So they conclude that the waste PP modified bituminous concrete mixtures are more durable, less moisture absorbing quality and also increase the performances of mixtures. The limitation of this research work is that there is no change in gradation as well as replacement of filler in modified waste plastic [3].

Nuha S. Mashaan, et. al. (2011) investigate the impact of different Crumb Rubber content with the physical, rheological and rutting resistance of rubberized bitumen. They conducted different laboratory tests to know the properties of bitumen binder with different rubber content just as "penetration test, ductility test, elastic recovery test and Dynamic Shear Rheometer (DSR) test". The end conclusion is that the adding of crumb rubber has provided an effect on physical property of Rubberized Binders by increasing elastic recovery value and by decreasing the penetration and ductility value. Their result also indicated that the rubber content could resist rutting deformation due to increasing traffic load in the pavement. The drawbacks of this paper is no change in gradation in rubber modified mix as well as no replacement of filler in the bituminous mixtures [4].

Praveen Kumar (2013) evaluate the sulfur modified binder in 1 to $6 \%$ with the weight of bitumen with a mixing temperature of $110^{\circ} \mathrm{C}$. The penetration, softening point, viscosity, Ductility, elastic recovery tests performed for checking various properties of the sulfur modified binder. The penetration and softening point improved just as correlating with virgin bitumen as well as the ageing performances should be within the limits. The drawback of this paper is not utilizing the properties of Sulfur modifier by PAV and DSR test as well as not investigating the Marshall Stability parameters as well as ITS test parameters to determine different effects on bituminous pavement [5].

Vahid Rezvani et. al. (2015) investigates the characteristics of limited interchange of bitumen with addition of sulfur in bituminous mixture. The comparison between properties of conventional bitumen and sulfur modified bitumen was conducted in this work. The process of addition of sulfur with natural bitumen, therafter mixed over aggregates. Lastly enhanced circumstances of SMA formulation concerning contamination with atmospheric problems have likewise projected [6].

Poorna Prajna et. al. (2015) states that the bituminous concrete mixes by considering aggregate combined index as $30 \%$ with sulfur as modifier. In this study the investigation should be done on the conventional Marshall Stability test properties of penetration grade 
(60/70 grade) of bitumen modified with sulfur modifier. The study of various effects of sulfur modifier also investigated by using different proportions in bituminous mixes [7].

Aditya K. Das et. al. (2017) stated Sulfur as adequate extender for virgin bitumen. The work has pursued for expanding a "modified binder in the laboratory using virgin bitumen(VG 30) with sulfur (S) and study the outcomes of ' $S$ ' on the viscosity, rheological, penetration index and storage stability with effects of short and long term aging. He observed that the modification of VG-30 with $2 \%$ of ' $\mathrm{S}$ ' by weight at $140{ }^{\circ} \mathrm{C}$ temperature and stirring time about $60 \mathrm{~min}$, developed a uniform modified bitumen binder [2].

By reviewing all the literatures, it has been found that the properties of sulfur modifier is most important parameter to improve the quality of bituminous binder. This research work states all the property investigations of bituminous binder combined with "Pressure Aging Vessel (PAV) test" and also checking impacts of Long term aging on engineering properties of Sulfur Modified bitumen.

\section{EXPERIMENTAL TEST TO STUDY THE PROPERTIES}

The present part of the paper speaks for the individual experimental tests on bituminous binder with or without sulfur modification. This part elaborates about the whole experimental studies performed from Material collection to tests performed and also defines about the basis of all the tests which could be performed in our institution laboratory.

A. Material Collection: The materials used in this research works are (i) Bitumen: The bitumen which is used for the experiment was supplied by Vikash Refiner HP Asphalt of viscosity grading 30 (VG 30). (ii) Modifier: The modifier used in this study was Sulfur which modified with VG 30 bitumen.

B. Preparation of sulfur modifiers with VG 30 bitumen: For preparation of sulfur modified binder $1 \mathrm{k} . \mathrm{g}$ of bitumen should be taken and sulfur is added in various proportions with a mixing temperature between $120^{\circ} \mathrm{C}$ to $130^{\circ} \mathrm{C}$.The sulfur is mixed with bitumen by a glass rod with mixing time of 30 minutes till the modifier is thoroughly mixed to get rid of voids present in bituminous binder.

C. Test to be conducted: There may be many tests conducted on bituminous binders to determine its various properties. But for deciding Physical Property only some, described tests are enough. The various tests performed for finding properties of SMB and unmodified binder (VG 30 bitumen) are described below.

- Penetration Test: The Penetration Test has executed to deciding consistency of bitumen with finding out indirect viscosity of bitumen at $25^{\circ} \mathrm{C}$ to recognize grade on solid and semi-solid substances like bitumen, tar and pitch. This test is also conducted for checking the hardness of bitumen. Penetration is the distance that the vertical needle can penetrate into the bituminous sample under a standard temperature, load and duration. It expressed in one tenths in millimetre. This test is conducted as per IS 1203-1978, IS 73-2006 [8].

- Softening point test:- It is the specific temperature at which bitumen begins to soften at a given set of conditions. It is also called Ring ball apparatus test. Softening point of bitumen is the temperature at which bitumen binders have an equal viscosity. Softening point test is performed as per IS 1205-1978 [9].

- Ductility test: This is the distance in $\mathrm{cm}$ during which the sample will be elongated before breaking. The binder material which possess less ductility will crack which causes damage to the pavement surface. The test has been standardized by BIS. This test is conducted as per IS1208-1978, IS-73-2006 [10]. 
- Elastic recovery test: It is calculated by determining the recovery of the bituminous binder thread generated after elongation of sample after cutting down by scissor at a standard set of conditions. This test is carried out as per IRC: SP 53-2002 [11].

- Viscosity test: That is the measure of resistance to flow. Viscosity is dependent upon the temperatures. It is reduced with increase in temperature. The range of viscosity of various types bituminous binders used in road construction vary considerably depends upon the grade and type of binder. This test is conducted in Book Field viscometer and Conducted as per ASTM D 4402-2006. According to ASTM D 4402-02, the rational viscometer test is conducted now a days to determine viscosity. For large range temperatures, Book field viscosmeter has being needed for deciding Viscosity of bitumen based on thermocel system. According to the variations of R.P.M of spindles for various shear rates, viscosity of bitumen is determined. According to ManualNo.M/85-150-P700,AddendumNo.D10-3311, Brookfield Engineering Laboratories, INC, the torque of the spindle should be at least $10 \%$ to get accurate viscosity. The spindles are chosen according to the different model of book field viscometer and the torque on the rotating spindle has required for detecting Relative Resistance of bitumen on certain temperature and shear rate. Various calibration factors are also used to change the torque value to determine the viscosity of bitumen [12][13].

- Rolling Thin Film Oven Test (RTFOT): It is conducted to measure impact of air and heat of asphalt binder on a moving film with the residues for additional testing. Ageing of bituminous binder occurs during mixing and service life. There are two types of ageing i.e. short term and long term ageing. Short-term ageing is performed by two methods i.e. Thin Film Oven (TFO) and Rolling Thin Film Oven (RTFO) test to determine the hardening of bitumen during mixing. This test is conducted as per AASHTO T 240 -13 and ASTM D 2872-04 [14].

- Pressure aging vessel (PAV) test: This test give simulated Long term aging of bituminous binder for physical property testing. Generally the RTFO sample of bitumen binder taken for PAV test. In this test the physical properties of bituminous binder after aging of 7 to 10 years can be checked out though bituminous binder disclosed with heat and pressure during long term aging. The bituminous binder placed in stainless steel pans and ages up to 20 hours in preheated vessel in a pressure of $2.10 \mathrm{Mpa}$. After the test the physical property tests of bitumen binder should be done. This test is conducted as per ASTM D6521, AASHTO R 28 and EN 14769 [15].

\section{EXPERIMENTAL SETUP}

This portion of the paper denotes different experimental setup, their description, importance of better modified bitumen are discussed. It describes the main goals of experimental investigations needed for the experimental works and finally describes the steps required for conducting these tests.

\subsection{Description of Test Procedures}

Penetration Test: In order to soften the bitumen, the bitumen is heated about or above in the temperature range of $75^{\circ} \mathrm{C}$ to $100^{\circ} \mathrm{C}$. The bitumen sample is thoroughly blended so that it makes the bitumen free from water and air bubbles. Then the sample is poured into $35 \mathrm{~mm}$ depth and then keep the sample for air cooling in atmosphere at 15 to $30^{\circ} \mathrm{C}$ for about 60 to 90 minutes and then sample is placed in a thermostatically controlled water bath at $25^{\circ} \mathrm{C}$ for 60 90 minutes. Then the sample is removed from water bath and placed under needle of penetrometer. The needle assembly is lowered through the adjusting screw and tip of the needle is just to touch the top of the sample and clamp is fixed. The initial reading of penetrometer is taken before releasing the needle. By pressing the knobs of penetrometer, the needle is released for a period of 5 seconds. And the final reading is taken by dial gauge. Removed the needle and then clean and dry the needle. By the same procedure three such measurements are taken and the average of three measurements is taken as penetration value. 
It is represented in $(1 / 10)^{\text {th }}$ in $\mathrm{mm}$. The figures shown below describes all about the procedure of penetration test .In figure 1(a) shows the penetrometer with samples during water cooling and figure 1(b) shows the penetrometer for measuring the penetration of bituminous binder having dial gauge reading in one tenth in mm attached with needle. As per IS 73 2006, the penetration value of Virgin bitumen (VG 30) should be 50 to 70 and according to IRC SP:532010 , the penetration value of modified bitumen is 50 to 80 at $25^{\circ} \mathrm{C}$. The results of this tests says about the hardness and softness property of bitumen. If the penetration values increases gradually means the binder gets softer and if reduces constantly means binder gets harder. [8][11].

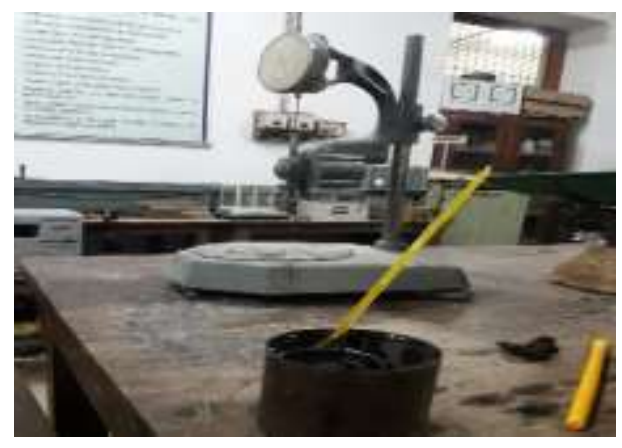

Figure 1 (a) Penetration test in laboratory

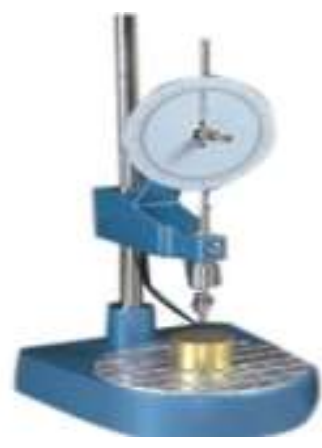

(b) Penetrometer (Image Source)

Softening Point Test: The bitumen has been preheated around a temperature between $75^{\circ} \mathrm{C}$ and $100^{\circ} \mathrm{C}$ just before it is fully converted in to fluid form and is poured over heated rings placed on a metal plate. Then rings are heated with outpouring hot bitumen keeping it on a plate of metal .For staying away from adhering of binder, solution of glycerin and dextrin coating is done to this. The rings are kept for air cooling about $30 \mathrm{~min}$, then surplus binder is cut down and circular ring has kept on stand with keeping heat of pure water about $5^{\circ} \mathrm{c}$ preserved about 15 minute. Then balls are put on binder from top. Degree of heat in which bitumen impartially contacts metal plate base known as "Softening point" and two observations are taken and their average is taken as result.

The figures displayed underneath describes the test procedures of Softening point test. Figure 2(a) shows the overall set up of starting point of Test to ending point of test with fitting thermometer on the ring ball apparatus with showing the red mark as temperature mark which shows the softening point of bituminous binder. Figure 2(b) represents the softening point beaker keeping over the electric heater with fitting thermometer above. As stated in IS 1205 1978 , Softening point value of VG 30 bitumen should be $40^{\circ} \mathrm{C}$ to $60^{\circ} \mathrm{C}$ and according to IRC SP: 53-2010,Softening point value for modified bitumen is minimum $55^{\circ} \mathrm{C}$. The softening point results increases means bitumen gets harder and decreases means it gets softer gradually.[9][11].
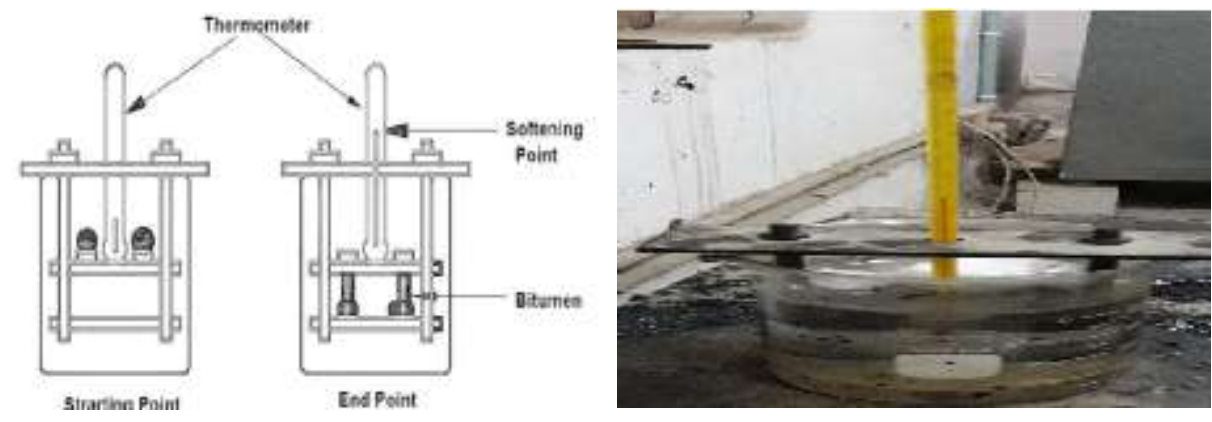

Figure 2 (a) Softening Point test procedure set up (b) Softening Point beaker on heater 


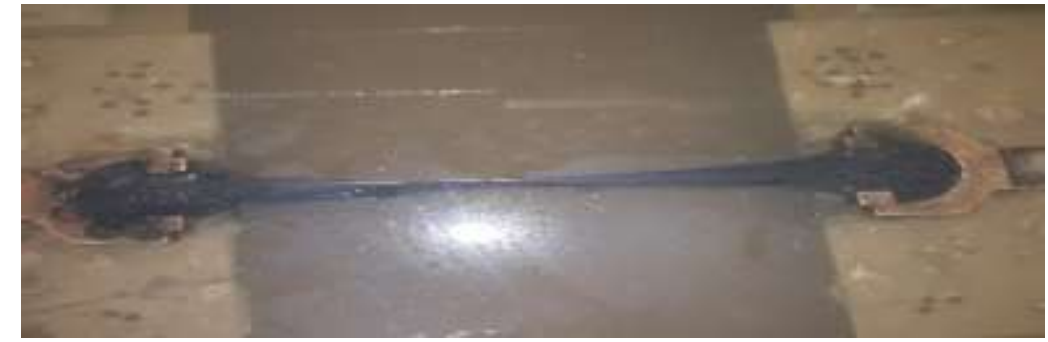

Figure 3 Elongated portion of binder on Ductility test (Laboratory work during research)

Ductility Test: The bitumen sample is melting at a temperature of $75^{\circ}$ to $100^{\circ} \mathrm{c}$ until it is converted in to fluid. Sample is kept on Mould assembly and placed on brass plate with applying solution of glycerine and dextrin at all the surface of Mould exposed to bitumen. The sample is kept for air cooling in room temperature for 30 to 40 minutes and then placed the sample in water bath at $27^{\circ} \mathrm{C}$ for 30 minutes. Extra binder is cut off by levelling the surface by using hot knife. After trimming again the sample is replaced in water bath maintained at $27^{\circ} \mathrm{C}$ for 85 to 95 minutes. The initial reading is set as zero by the pointer mark and then machine gets started. The point at which the bitumen thread of specimen breaks and the distance between initial and that point, is denoted in $\mathrm{cm}$ known as ductility value. Fig 3 shows the bitumen samples on briquette mould elongated up to certain point during the test. As stated by IS: 1208-1978, IS 73 1961, the ductility value is minimum 40 and maximum 100 for VG 30 bitumen and as reported by IRC SP: 532010 the ductility value is maximum 100.A certain minimum ductility value is considered essential for a bitumen binder for satisfactory pavement performance. The ductility values of bitumen varies from 5 to over 100 [10][11].

Elastic Recovery Test: The sample preparation of this test is to be done as per ductility test but in the elastic recovery Mould. The sample is elongated at the specified rate of $50 \pm 2.5$ $\mathrm{mm}$ per minute at the specified temperature to a deformation of $10 \mathrm{~cm}$. After $10 \mathrm{~cm}$ deformation, the specimen is cut in to halves at the mid-point using scissors. The sample is kept on water bath for one hour at certain temperature. After 1 hour, we observe that the elongated part of specimens is come back to its original positions so that both half of samples touch each other. This length of the recombined specimen is measured as ' $D$ ' $\mathrm{cm}$. Elastic recovery in percentage is given by

$$
\text { Elastic Recovery }(\%)=\frac{100(10-D)}{10}
$$

Figure 4 shows the half portion cutting sample in the Mould on ductility machine. The elastic recovery value is minimum $60 \%$ as per ASTM D 6084 for VG 30 and also minimum 60\% for modified bitumen as per IRC SP:53 2010 [11].

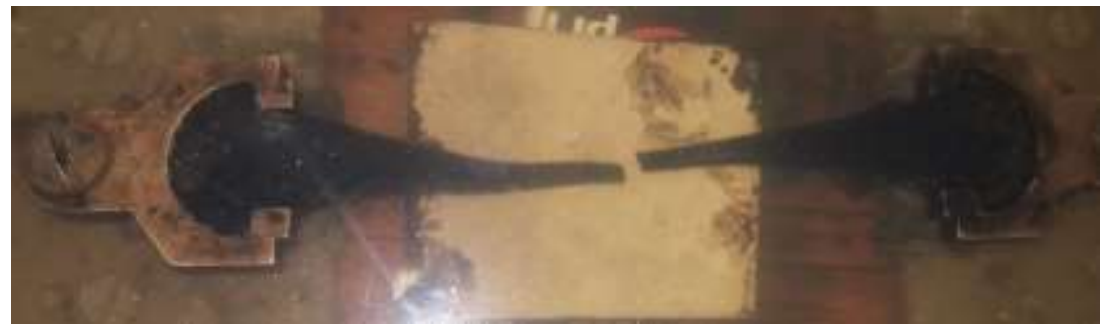

Figure 4 Elastic recovery sample (Laboratory work during research)

Viscosity Test: Viscosity is the measure of fluid resistance to flow. At given shear rate, the fluid viscosity is measured by Book field Viscometer .Various methods are adopted for viscosity measurements. According to Bureau of Indian Standards, the absolute viscosity is 
determined at $60^{\circ} \mathrm{C}$.Assembling of laboratory stand should be done first. Place the Viscometer safely on Brookfield Laboratory stand. Referring to bubble level in the Instrument, level the viscometer. Verify the viscous meter power requirement to match with our source before connecting the power. Then select the spindle according to our instrument model .Adjustment of spindle should be conducted by clamping screw and then heat the sample and put it on the stand at $60^{\circ} \mathrm{C}$,turn on the switch and record the data representing on the digital display of Book Field Viscometer. As per IS 732006 and IS 1206 part 2,the viscosity test values for virgin bitumen 2400 to 3600 poise and also 2400 to 3600 poise for modified bitumen as per IS 1206 part 2 [12][13].

Rolling Thin Film Oven Test: In RTFO test, $35 \mathrm{gm}$. of samples are loaded on the jar and kept for 85 minutes at $163^{\circ} \mathrm{C}$ on R.T.F.O machine. Remove the jars and make it cool up to certain time and clean the jar by removing the samples from jar. The percentage loss of sample is also checked out. The effect of heat and air can be obtained by conducting physical tests after and before the oven treatment. Figure 5(a) shows the heating glass jars loaded with bitumen samples, figure 5(b) represents the samples rotating on R.T.F.O machine at $163^{\circ} \mathrm{c}$ and $5(\mathrm{c})$ shows glass jars putting on hot plate after removing from R.T.F.O machine to remove bitumen binders from the jar. As per IRC SP:53 2010 ,the modified binder properties results after R.T.F.O test are described as the loss in mass is maximum $1.0 \%$,increase in softening point is maximum $6^{\circ} \mathrm{C}$ at temperature of $20^{\circ} \mathrm{C}$ to $35^{\circ} \mathrm{C}$, reduction in penetration value at $25^{\circ} \mathrm{C}$ is maximum 35 and elastic recovery value is minimum $50 \%$.[14]

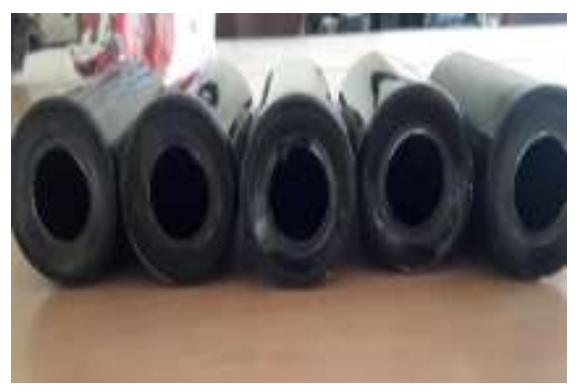

(a)

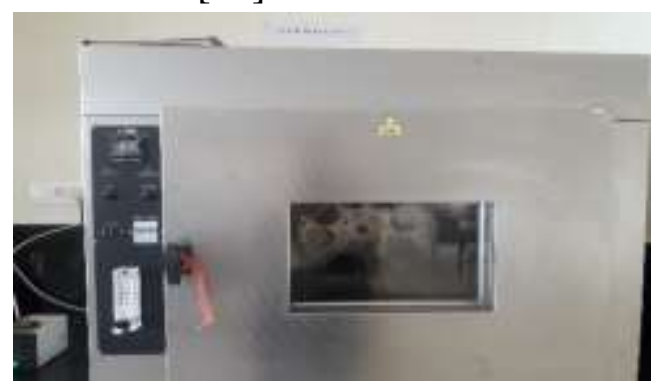

(b)

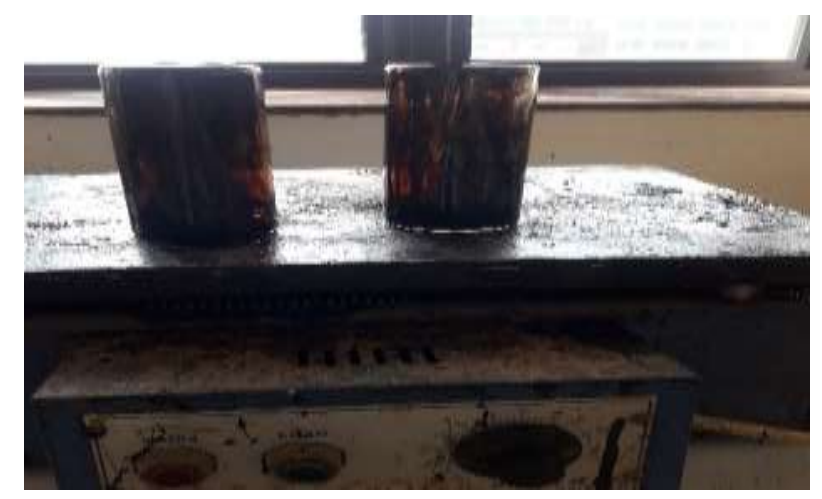

(c)

Figure 5 (a) Heat sample on glass jar (b) Samples rotating on R.T.F.O machine (c) Samples heated on hot plate after test (Laboratory work during research)

Pressure aging vessel Test: This gives simulated long term aged bituminous binder for testing the engineering property. Bituminous binder is liable to heat and pressure to reproduce in-service aging over a period of 7 to 10 year. PAV procedure takes RTFO samples by heating and placing them in stainless steel pans and then ages them for 20 hours in PAV testing vessel which is pressurized with $2.10 \mathrm{Mpa}$. Then this samples are stored for using in physical property tests. Though PAV test samples should be tested on Dynamic Shear Rheometer 
(DSR) but due to unavailability of laboratory set up, we could conduct the property tests of PAV samples to observe the performances of virgin as well as sulfur modified binder.[15]

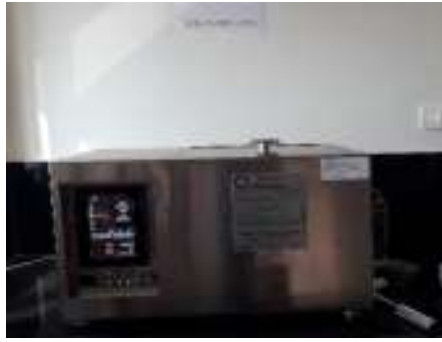

(a)

(b)

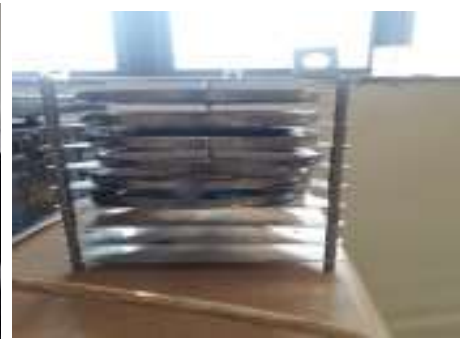

(c)

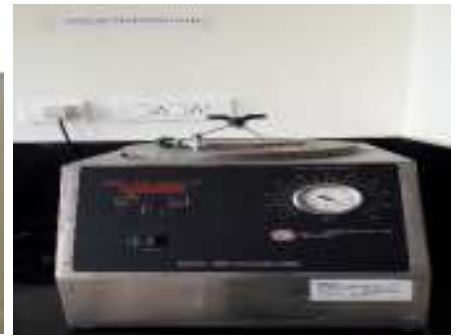

(b) Samples kept in PAV Machine (c) Vaccum Degassing

Figure 6: (a) Sample in stainless steel pans (b) Samples kept in PAV Machine (c)
Oven (Laboratory work during research at IIT,Bbsr)

\section{EXPERIMENTAL RESULTS AND DISCUSSION}

The following experiments are conducted to investigate about property of bituminous binder with varying the sulfur content percentage wise, which acts as modifier. Different experiments and their outcomes are given in this section.

\subsection{Penetration Test}

The penetration value of modified and unmodified bituminous binders are represented in table I.

Table 1 Penetration Values

\begin{tabular}{|l|c|c|c|}
\hline $\begin{array}{c}\text { Types of } \\
\text { binder }\end{array}$ & $\begin{array}{c}\text { Modifier } \\
\text { content } \mathbf{( \% )}\end{array}$ & $\begin{array}{c}\text { Penetration } \\
\text { value at } \mathbf{2 5}^{\circ} \mathbf{C} \\
(\mathbf{1 / 1 0} \text { th } \mathbf{~ i n ~} \mathbf{~ m m})\end{array}$ & $\begin{array}{c}\text { Variation of results in } \\
\text { Percentage as } \\
\text { compared with Virgin } \\
\text { Bitumen (VG 30) (\%) }\end{array}$ \\
\hline VG 30 & 0 & 67 & 0 \\
\hline VG 30 & 1 & 65 & 2.98 \\
\cline { 2 - 4 }+ \\
\cline { 2 - 4 } Sulfur & 2 & 64 & 4.47 \\
\cline { 2 - 4 } & 3 & 63 & 5.97 \\
\cline { 2 - 4 } & 4 & 59 & 11.94 \\
\cline { 2 - 4 } & 5 & 57 & 14.92 \\
\cline { 2 - 4 } & 6 & 56 & 16.41 \\
\cline { 2 - 4 } & 7 & 54 & 19.40 \\
\cline { 2 - 4 } & 8 & 52 & 22.38 \\
\hline
\end{tabular}

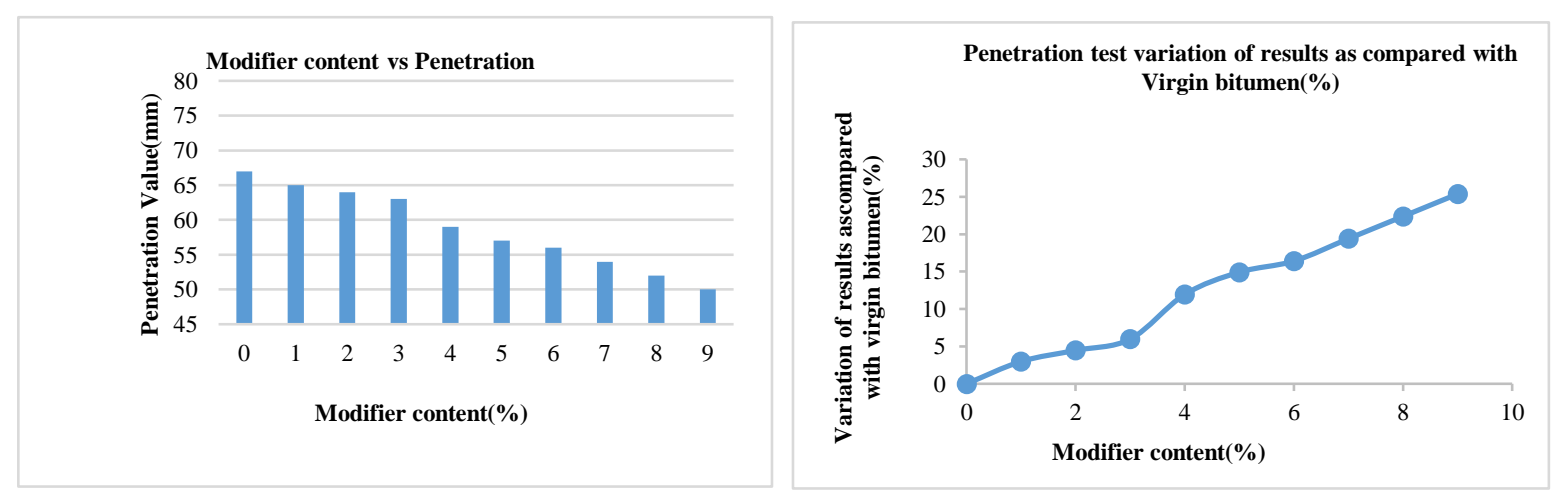

Figure 7: Variation of Penetration value Figure 7 Penetration test variation of results as compared with Virgin bitumen $(\%)$

(Experimental results obtained from laboratory works) 
The penetration value of bitumen gradually decreases after modification with sulfur. It states the bitumen gradually gets harder after addition of Sulfur on bitumen. The variation of penetration value in percentage as compared with virgin bitumen is gradually increases from $0 \%$ to $25.37 \%$ which is too large as compare with virgin bitumen. So we found that sulfur modified binder perform better results than virgin bitumen. Figure 7 shows the inflation rate of penetration result for varying percentages of modifier.

\subsection{Softening Point Value}

The softening point value of modified and unmodified bituminous binders are represented in the below table 2 and fig 2 .

Table 2 Softening Point Values

\begin{tabular}{|c|c|c|c|}
\hline $\begin{array}{c}\text { Types } \\
\text { of } \\
\text { binder }\end{array}$ & $\begin{array}{c}\text { Modifier } \\
\text { content } \\
(\boldsymbol{\%})\end{array}$ & $\begin{array}{c}\text { Softening } \\
\text { point }\left({ }^{\circ} \mathbf{C}\right)\end{array}$ & $\begin{array}{c}\text { Variation of results } \\
\text { in Percentage as } \\
\text { compared with } \\
\text { Virgin Bitumen (VG } \\
\mathbf{3 0 )}(\boldsymbol{\%})\end{array}$ \\
\hline VG 30 & 0 & 46.5 & 0 \\
\hline VG 30 & 1 & 54.5 & 17.20 \\
\cline { 2 - 4 }+ \\
\cline { 2 - 4 } Sulfur & 2 & 55.5 & 19.35 \\
\cline { 2 - 4 } & 3 & 56 & 20.43 \\
\cline { 2 - 4 } & 4 & 56.5 & 21.50 \\
\cline { 2 - 4 } & 5 & 57 & 22.58 \\
\cline { 2 - 4 } & 6 & 59 & 26.88 \\
\cline { 2 - 4 } & 7 & 60.5 & 30.10 \\
\cline { 2 - 4 } & 8 & 63 & 35.483 \\
\hline
\end{tabular}

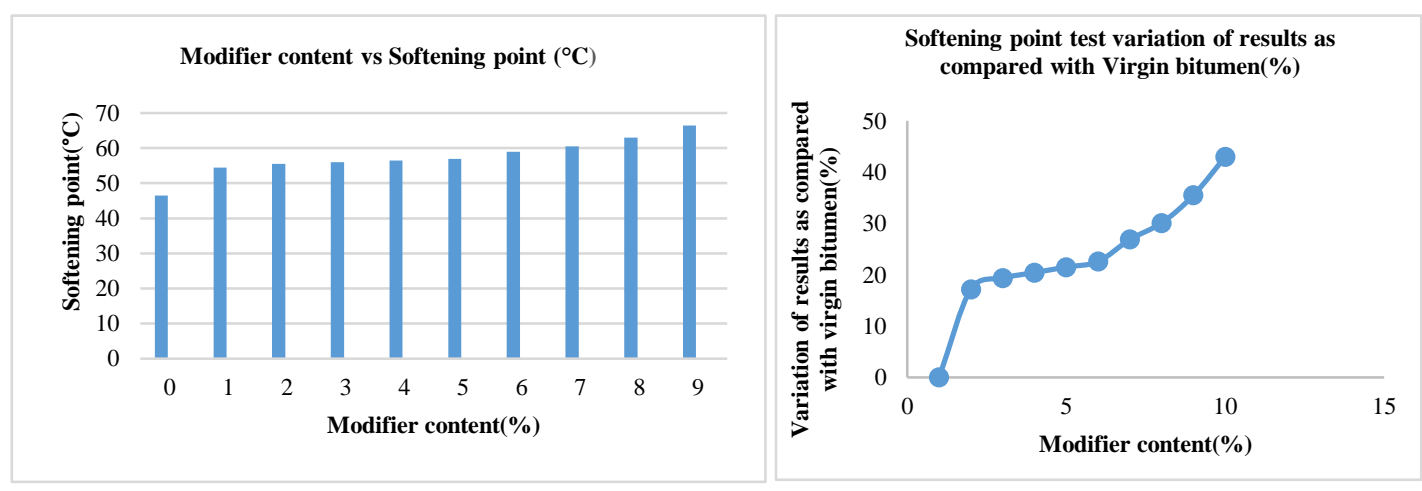

Figure 8: Variation of Softening Point value Figure 9: Softening point test variation of results as compared with virgin bitumen(\%)

(Experimental results obtained from laboratory works)

The Softening Point value of bitumen gradually increases shows in results above. It seems that bitumen gets harder after modification with Sulfur. The deviation of softening point value in percentage as compared with virgin bitumen is increases from $0 \%$ to $43.01 \%$. It is so large as compared with virgin bitumen means sulfur modified binder has higher quality than VG 30 and also all the results should be within the specified range. Figure 9 gives the rising of variation results of softening point test as compared with virgin bitumen.

\subsection{Ductility Value}

The ductility values of modified and unmodified binders are calculated in the below tables and figure. 
Table 3 Ductility Values

\begin{tabular}{|l|c|c|c|}
\hline $\begin{array}{c}\text { Types of } \\
\text { binder }\end{array}$ & $\begin{array}{c}\text { Modifier } \\
\text { content } \\
(\boldsymbol{\%})\end{array}$ & $\begin{array}{c}\text { Ductility } \\
\text { value(cm) }\end{array}$ & $\begin{array}{c}\text { Variation of results in } \\
\text { Percentage as compared } \\
\text { with Virgin Bitumen (VG } \\
\text { 30) (\%) }\end{array}$ \\
\hline VG 30 & 0 & 74 & 0 \\
\hline \multirow{3}{*}{$\begin{array}{l}+ \\
\text { Sulfur } 30\end{array}$} & 1 & 71 & -4.05 \\
\cline { 2 - 4 } & 2 & 68 & -8.10 \\
\cline { 2 - 4 } & 3 & 62 & -16.216 \\
\cline { 2 - 4 } & 4 & 58 & -21.62 \\
\cline { 2 - 4 } & 5 & 55 & -25.67 \\
\cline { 2 - 4 } & 6 & 53 & -28.378 \\
\cline { 2 - 4 } & 7 & 52 & -29.792 \\
\cline { 2 - 4 } & 8 & 51 & -31.081 \\
\cline { 2 - 4 } & 9 & 49 & -33.783 \\
\hline
\end{tabular}
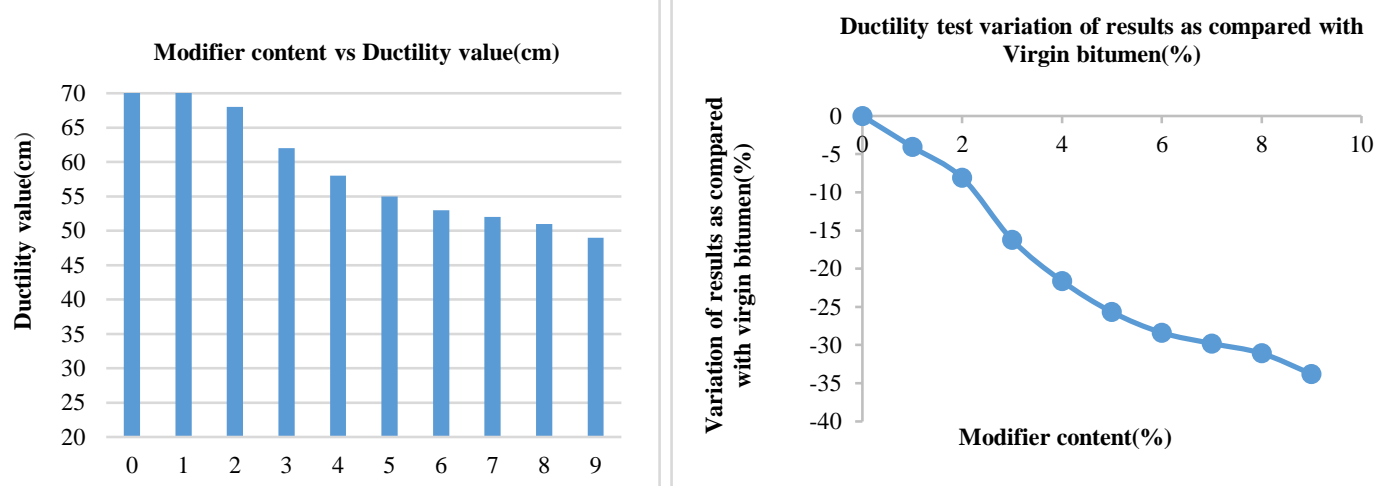

Figure 10 Variation of Ductility value

Figure 11 Ductility test variation of results as compared with Virgin bitumen $(\%)$

From the results shows above, the ductility value gradually decreases after addition of sulfur in bitumen which shows bitumen gets harder. The change of percentages of ductility value for Sulfur modified bitumen as compared with virgin bitumen maximized from $0 \%$ to $33.783 \%$ which is more suitable than virgin bitumen. The decreasing rate of ductility variation results have been given in figure 11 .

\subsection{Elastic Recovery Value}

The elastic recovery value of modified and unmodified binders are represented in the below table and figure below

Table 4 Elastic Recovery Values

\begin{tabular}{|l|c|c|c|}
\hline $\begin{array}{c}\text { Types of } \\
\text { binder }\end{array}$ & $\begin{array}{c}\text { Modifier } \\
\text { content (\%) }\end{array}$ & $\begin{array}{c}\text { Elastic } \\
\text { recovery (\%) }\end{array}$ & $\begin{array}{c}\text { Variation of results in Percentage as } \\
\text { compared with Virgin Bitumen (VG 30) (\%) }\end{array}$ \\
\hline VG 30 & 0 & 10 & 0 \\
\hline \multirow{3}{*}{$\begin{array}{l}\text { VG 30 } \\
\text { Sulfur }\end{array}$} & 1 & 15 & 50 \\
\cline { 2 - 4 } & 2 & 17 & 70 \\
\cline { 2 - 4 } & 3 & 18 & 80 \\
\cline { 2 - 4 } & 4 & 19 & 90 \\
\cline { 2 - 4 } & 5 & 21 & 110 \\
\cline { 2 - 4 } & 6 & 22 & 120 \\
\cline { 2 - 4 } & 7 & 24 & 140 \\
\cline { 2 - 4 } & 8 & 27 & 170 \\
\hline
\end{tabular}



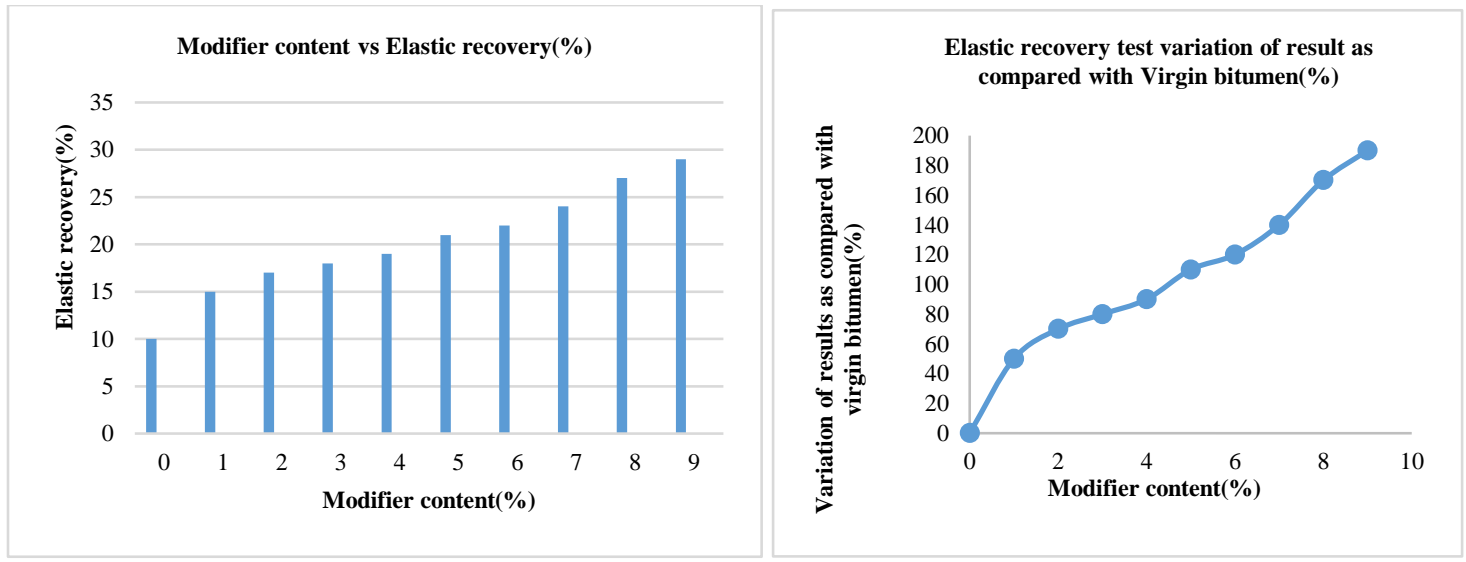

Figure 12. Variation of Elastic recovery value as compared

Figure 13. Elastic recovery test variation of result with virgin bitumen $(\%)$

The Elastic recovery value gradually increases with rising in modifier Content means the modified bitumen can deviated back to its original position early and the variation of results in percentage of sulfur modifier as compared with virgin bitumen has raised from $0 \%$ to $190 \%$ which is a huge transformation in properties. The growing rate of Elastic recovery results as compared with VG 30 bitumen in figure 13.

\subsection{Viscosity Value}

The viscosity values of modified and unmodified binders are shown in the below table and figure.

Table 5 Viscosity Values

\begin{tabular}{|l|c|c|c|}
\hline $\begin{array}{c}\text { Types of } \\
\text { binder }\end{array}$ & $\begin{array}{c}\text { Modifier } \\
\text { content (\%) }\end{array}$ & $\begin{array}{c}\text { Viscosity } \\
\text { value(cp) }\end{array}$ & $\begin{array}{c}\text { Variation of results in Percentage as compared } \\
\text { with Virgin Bitumen (VG 30) (\%) }\end{array}$ \\
\hline VG 30 & 0 & 107000 & 0 \\
\hline VG 30 & 1 & 118700 & 10.93 \\
\cline { 2 - 4 } & 2 & 123100 & 15.04 \\
\cline { 2 - 4 } Sulfur & 3 & 136400 & 27.47 \\
\cline { 2 - 4 } & 4 & 161400 & 50.84 \\
\cline { 2 - 4 } & 5 & 179500 & 67.75 \\
\cline { 2 - 4 } & 6 & 184800 & 72.71 \\
\cline { 2 - 4 } & 7 & 196800 & 83.92 \\
\cline { 2 - 4 } & 8 & 214400 & 100.37 \\
\cline { 2 - 4 } & 9 & 237400 & 121.86 \\
\hline
\end{tabular}

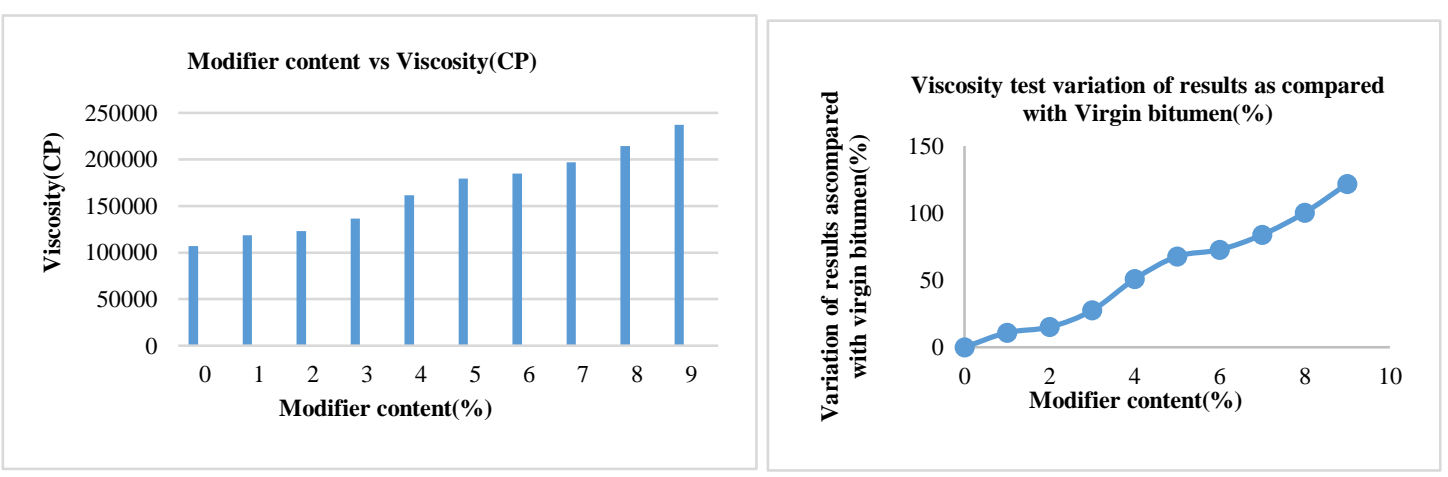

Figure 14: Variation of Viscosity value Figure 15: Viscosity test variation results as compared with virgin bitumen(\%) 
The Results above shows that the rising in modifier content in bitumen rises the viscosity value of bitumen which states that the sulfur modified bitumen hardens the bitumen. The modification in percentage change in viscosity values of sulfur modified bitumen as compared with virgin bitumen is increased from $0 \%$ to $121.865 \%$. Figure 15 performs the increasing variation results as compared with VG 30 bitumen.

\section{OPTIMUM DOSE OF SULFUR CONTENT}

The requirement of penetration, softening point, viscosity, Elastic recovery contented at $2 \%$ sulfur as per IRC SP: 53 -2002 and IS 154622004.

\section{AGING EFFECT}

The ageing effect can be represented by the physical property checking of various binders after RTFO \& PAV test. The different changes in the physical properties of bitumen binders are represented below.

\subsection{RTFO Physical Properties}

Table 4 Physical Properties of R.T.F.O Test

\begin{tabular}{|c|c|c|}
\hline Designation & Binder type & Test Results \\
\hline \multirow{2}{*}{$\begin{array}{l}\text { Loss in weight } \\
(\%)\end{array}$} & VG 30 & $0.010 \%$ \\
\hline & $2 \%$ Sulfur modified bitumen & $0.020 \%$ \\
\hline \multirow{2}{*}{$\begin{array}{l}\text { Increase in } \\
\text { softening } \\
\text { point }\left({ }^{\circ} \mathrm{C}\right) \\
\end{array}$} & VG 30 & $6.25^{\circ} \mathrm{c}$ \\
\hline & $2 \%$ sulfur modified bitumen & $3^{\circ} \mathrm{C}$ \\
\hline \multirow{2}{*}{$\begin{array}{l}\text { Reduce in } \\
\text { Penetration at } \\
25^{\circ} \mathrm{C}\end{array}$} & VG 30 & 21.34 \\
\hline & $2 \%$ sulfur modified bitumen & 19.67 \\
\hline \multirow{2}{*}{$\begin{array}{l}\text { Increase in } \\
\text { viscosity }(\mathrm{CP})\end{array}$} & VG 30 & 10700 \\
\hline & $2 \%$ sulfur modified bitumen & 116900 \\
\hline \multirow{2}{*}{$\begin{array}{l}\text { Elastic recovery } \\
\text { at } 25^{\circ} \mathrm{C}(\%)\end{array}$} & VG 30 & 8 \\
\hline & $2 \%$ Sulfur modified bitumen & 12 \\
\hline
\end{tabular}

The physical properties of samples after R.T.F.O test are within the permissible limit [7]. The loss in weight in percentage is maximum $1 \%$ for modified binder after R.T.F.O Test as per IRC SP:53 2010 and this result for VG 30 and 2\% sulfur modified binder is $0.010 \%$ and $0.020 \%$ respectively which should be with in required limit. All other properties like softening point, Penetration, Viscosity and Elastic recovery values are within the permissible limit and 2\% sulfur modified binder has better results compared with VG 30 bitumen. [4]

\subsection{PAV Physical Properties}

Table 7 Physical Properties of PAV Samples

\begin{tabular}{|c|c|c|}
\hline Designation & Binder type & Test Results \\
\hline \multirow{2}{*}{ Loss in weight (\%) } & VG 30 & 0.020 \\
\hline & $2 \%$ Sulfur modified bitumen & 0.035 \\
\hline \multirow{2}{*}{$\begin{array}{l}\text { Increase in } \\
\text { softening point }\left({ }^{\circ} \mathrm{C}\right)\end{array}$} & VG 30 & $12.25^{\circ}$ \\
\hline & $2 \%$ Sulfur modified bitumen & $7.4^{\circ}$ \\
\hline \multirow{2}{*}{$\begin{array}{l}\text { Reduce in } \\
\text { Penetration at } 25^{\circ} \mathrm{C}\end{array}$} & VG 30 & 27.4 \\
\hline & $2 \%$ Sulfur modified bitumen & 23.76 \\
\hline \multirow{2}{*}{$\begin{array}{l}\text { Increase in } \\
\text { viscosity }\end{array}$} & VG 30 & 9970 \\
\hline & $2 \%$ Sulfur modified bitumen & 105400 \\
\hline \multirow{2}{*}{$\begin{array}{l}\text { Elastic recovery at } \\
25^{\circ} \mathrm{C}(\%)\end{array}$} & VG 30 & 5 \\
\hline & $2 \%$ Sulfur modified bitumen & 8 \\
\hline
\end{tabular}


The PAV test samples were taken for the properties test of Virgin as well as Sulfur modified binder. Here we observe that the Sulfur modified binder have maximum loss in weight in comparison to VG 30 binder .Inflation of Softening point is less, reduction of penetration value is less, raise in viscosity is high and elastic recovery is more as comparison with Virgin bitumen (VG 30). The overall results denotes that after long term aging also the modified binder properties performs best rather than VG 30 binder.

\section{CONCLUSION}

Various experiments have been organized to analyze the different property of the sulfur modified bitumen with ageing with respect to virgin bitumen. Addition of sulfur as modifier in bitumen changes the some of the physical properties of sulfur modified bitumen as pavement material. Moreover, the variation of the percentage of the sulfur modifier in bitumen also changes the physical properties reasonably. Figure 6, 7 and 8,9 shows the Penetration and softening point values which are increased in increasing percentages of sulfur. It also provides less penetration value and higher softening point as comparison with virgin bitumen. From figure 10.11,12 and 13, we obtained the ductility and elastic recovery value which are decreased and increased respectively with increase in sulfur content. The viscosity value increases as compare to neat bitumen found from figure 14,15. The impact of aging of sulfur Modified binder is within the acceptable range and provides better result as compared with virgin bitumen which results were notified in table 6 and 7 and all the criteria for modified binder satisfied as per IRC SP: 53 -2002. Due to certain laboratory availability of instruments the DSR test of binders cannot be conducted and properties only checked out. But by conducting such property analysis we observed that modified binder has good quality than Virgin bitumen.

\section{REFERENCES}

[1] Aditya Kumar Das, Mahabir Panda (2017), "Investigation on rheological performance of sulphur modified bitumen (SMB) binders" Journals of construction and Building Materials 149 (2017) 724-732.

[2] ASTM D 2872 (2004), "Standard Test Method for Effect of Heat and Air on a Moving Film of Asphalt (Rolling Thin-Film Oven Test)"

[3] ASTM D 4402. (2006). "Standard Test Method for Viscosity Determination of Asphalt at Elevated Temperatures Using a Rotational Viscometer".

[4] ASTM D6521, Standard Practice for Accelerated Aging of Asphalt Binder Using a Pressurized Aging Vessel (PAV).

[5] Dr. S.K. Khanna, Dr. C.E.Justo, Dr. A. Veeraragavan, "Highway materials and pavement testing”, Revised Fifth edition 2009.

[6] E.R. Souaya a, S.A. Elkholy b, A.M.M. Abd El-Rahman b, M. El-Shafie b, I.M. Ibrahim b, Z.L. Abo-Shanab b, "Partial substitution of asphalt pavement with modified sulfur," Egyptian Journal of Petroleum (2015) 24, 483-491.

[7] Gawel, I. (2000). "Sulfur-modified asphalts", Journal of asphaltenes and asphalts, Elsevier Science Ltd, 2, 515-535.

[8] Ghaly, N. (2008). "Effect of Sulfur on the Storage Stability of Tire Rubber Modified Asphalt", World Journal of Chemistry, 3(2), 42-50. 
[9] H. Kazemi Esfeh, B. Ghanavati, and T. Ghale Golabi, "Properties of Modified Bitumen Obtained from Natural Bitumen by Adding Pyrolysis Fuel Oil, International Journal of Chemical Engineering and Applications, Vol. 2 , No. 3 , June 2011.

[10] https://civilblog.org/2015/04/17/6-factors-influencing-aging-of-bitumen-binders.

[11] https://www.slideshare.net/SushmithaSushie/aging-of-bitumen-33179661

[12] IRC SP: 53 -2002 Guidelines on Use of Polymer and Rubber Modified Bitumen in Road Construction", Indian Road Congress, New Delhi.

[13] IS 1203 (1978), "Methods for testing Tar and Bituminous materials, Penetration test, Bureau of Indian Standards, New Delhi.

[14] IS 1205 (1978), "Methods for testing Tar and Bituminous materials, Softening point test, Bureau of Indian Standards, New Delhi.

[15] IS 1208 (1978), "Methods for testing Tar and Bituminous materials, Ductility test, Bureau of Indian Standards, New Delhi.

[16] Jiqing Zhu, Bjorn Birgisson, Niki Kringos, "Polymer Modification of Bitumen: Advances and challenges, "European Polymer Journal, 54: 18-38, http://dx.doi.org/10.1016/j.eurpolymj.2014.02.005.

[17] Jyh-Dong Lin, Shih-Huang Chen, Pei Liu, \& Jian-Neng Wang: Modified Toughness used to evaluate the Effect of Polymer Modified Asphalt on Stonic Mastic Asphalt, Journal of the Chinese Institute of Engineers, vol. 27, No. 7, pp. 1013-1020, 2004.

[18] Mahabir Panda, Jhunarani Ojha, Siddharth Purohit, "Development and Evaluation of Sulphur Modified Bitumen Binder," Proc. of the Eighth Intl. Conf. on Maintenance and Rehabilitation of Pavements, ISBN: 978-981-11-0449-7: : doi:10.3850/978-981-11-04497-137-cd

[19] Manual No. M/85-150-P700Addendum No.D10-3311, Brookfield Engineering Laboratories, INC.

[20] Nuha S. Mashaan (2011), "Effect of Crumb rubber Concentration on physical and rheological properties of rubberized bitumen binders", International Journal of Physical Sciences, Vol 6(4), pp. 684-690.

[21] P. Prajna S, M. Ilyas Anjum,"Suitability of sulphur as modifier in bitumen for road construction ", IJRET, Volume 4, 2015.

[22] Prabir Kumar Das, "Laboratory: Binder rheology and ageing", AF2903 Highway Construction and Maintenance, KTH Vetenskap OCH Konst, Royal Institute of Technology, Stockholm.

[23] Praveen Kumar (2013)." Evaluation of Physical Properties of Sulfur Modified Bitumen and its Resistance to Ageing," Elixir Chem. Eng. 55A (2013) 13104-13107.

[24] Researchgate.net/figure/Softening-Point-test-setup_fig3_305699066.

[25] S.A. Elkholy, A.M.M. Abd El-Rahman, M. El-Shafie, Z.L. Abo-Shanab, "Physical and rheological properties of modified sulfur asphalt binder," Egyptian Petroleum Research Institute (E.P.R.I.), Petroleum Applications Department, Asphalt Lab., Egypt, 1996- 
6814/_ 2018 Chinese Society of Pavement Engineering. Production and hosting by Elsevier B.V.

[26] Sabina, Tabrez A khan (2009), "Performance Evaluation of Waste plastic", Journal of Scientific and Industrial Research, Vol.68, pp 975-979

[27] Sabina, T. A Khan, Sangita, D K Sharma, B.M Sharma, "Performance of critical analysis of waste plastic "Journal of scientific \& Industrial Research, Vol-68, 2009.

[28] Serhiy Pyshyev, Volodymyr Gunka, Yuriy Grytsenko and Michael Bratychak, "Polymer Modified Bitumen: Review," Chemistry and Chemical Technology December 2016.

[29] V. S. Punith and A.Veeraragavan: Behavior of Asphalt Concrete Mixtures with Reclaimed Polyethylene as Additive, Journal of Materials in Civil Engineering, Vol. 19, No. 6, June $1,2007$.

[30] Vahid Rezvani, Hassan Saghi; Characteristics and preparation method of sulfur extended asphalt mixtures, American Journal of Civil Engineering, 2015. 